\title{
THE ELECTRICAL ACTIVITY OF SPINAL GANGLION CELLS INVESTIGATED WITH INTRACELLULAR MICROELECTRODES
}

\author{
MASAO ITO* \\ Department of Physiology, College of Medicine, University of Kumamoto
}

Since the intracelluar recording of the electrical activity of nerve cells was initiated by Brock, Coombs and Eccles (1952) on the spinal motoneurones of cats, considerable amounts of investigations have been made on various tissues by many workers, i.e., on motoneurones of cats (see Eccles, 1953, 1957), motoneurones of toads (Araki, Otani and Furukawa, 1953; Araki and Otani, 1955), stretch receptor cells of crayfish (Eyzaguirre and Kuffler, $1955 \mathrm{a}, \mathrm{b})$, svmpathetic ganglion cells of rabbits (R. M. Eccles, 1955) and etc.

Large cells of the spinal ganglion have been also noticed as a suitable material for studying activities of the nerve cell, because they have a simple monopolar configuration (Lenhossék, 1886) and can be impaled under the direct microscopical control. However, the work of Svaetichin on frog's spinal ganglion cells (1951) were limited to the analysis of extracellularly recorded potentials, and the intracellular recording from the ones of cultured chick embryo made by Crain (1956) seems to be insufficient to understand the activity of monopolar cells, because the cultured cells differ from the ones of adult animals both in the histological configuration and in the physiological conditions. The experiments presented here were undertaken to record potentials intracellularly from toad's spinal ganglion cells and to analyse their activity by the aid of both indirect and direct stimulation.

In order to apply direct stimuli to the impaled cell membrane, Araki and Otani (1955) employed a bridge circuit and used one and the same electrode both for recording and for stimulation, and Coombs, Eccles and Fatt (1955) adopted double-barrelled microelectrodes using one barrel for recording and the other for stimulating. The former method was employed in the present experiments, because with this method the artefacts of stimuli are much smaller than with the latter.

When microelectrodes are used for intracellular recording and for direct stimulation, there arise four important problems, that is: (1) high fidelity of the preamplifier for the use of high resistance microelectrodes, (2) compensation of the resting potential in the stimulating circuit, (3) measurement of the direct stimulating current and (4) cancelling of the potential change caused by stimulating currents through the microelectrode. In order to solve these problems, a special input circuit was deviced and used throughout the experiments.

Received for publication August 5, 1957.

* 伊藤正男

Present adress: Department of Physiology, School of Medicine, Tokyo University. 
This paper will describe this circuit, and then intracellularly recorded potentials and membrane properties of the spinal ganglion cells. The analysis of the conduction taking place from the axon to the cell will be reported elsewhere.

\section{METHODS}

Preparation. Toads (Bufo vulgaris formosus) were used throughout the experiments. The vertebral column was opened from the ventral side and one of the $L_{8}-L_{9}$ spinal ganglions was dissected out with the dorsal root and the peripheral nerve attached. The ventral root was cut off close to the ganglion and the connective tissue covering the surface of the ganglion was taken off carefully under the binocular microscope with the magnification of $40 \times$. Then it was mounted on Ringer bath and covered with a thin layer of the solution. Illumination was provided by light focussed to the cells from beneath by a condensor lens inserted just under the Ringer bath. With the mangnification of $120 \times$ the contour of cells in the surface layer of the ganglion could be well recognized without staining, and their approximate diameter was measured by an eyepiece micrometer. The microelectrode held by a micromanuplator of Peterfi's type was inserted vertically into cells. The stimulating electrodes of silver wire were set both on the peripheral nerve and on the dorsal root. For the purpose of introducing the direct stimulating current to the cell membrane the microelectrode was connected to an output of a stimulator through a resistor $R_{s}$ of $100 \mathrm{M} \Omega$ (fig. 1 ).

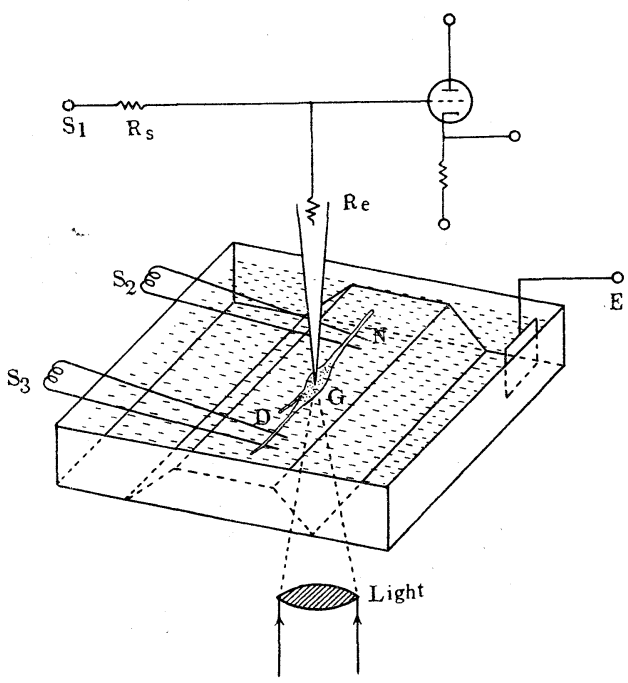

FIG. 1. Diagram of arrangement for stimulating and recording from the spinal ganglion cells. $G$; spinal ganglion, $N$; peripheral nerve, $D$; dorsal root, $R_{e}$; microelectrode, $R_{s}$; $100 \mathrm{M} \Omega$ resistaor, $S_{2}$ and $S_{3}$; stimulating electrodes of silver wire. The grid of the input cathode follower was connected to the $\mathrm{KCl}$ solution filled in the microelectrode through $\mathrm{Ag} \cdot \mathrm{AgCl}$ wire and a silver plate $E$ was used for connection with the Ringer bath. Both the peripheral nerve and the dorsal root were fixed by small blocks of cotton wool and the parts of them attached to the stimulating electrodes were covered by vaseline, which were omitted from the figure.

Preamplifier. When the cell is impaled by a microelectrode, the inside and the outside of the cell membrane are connected through $R_{s}$ as is shown in fig. $2(a)$, and therefore currents originated from the membrane resting potential flow through this circuit. This depolarising current is as large as $10^{-9} \mathrm{~A}$, which 
is of the same order as the rheobasic current of cells. This current can be prevented by inserting the electromotive force of opposite sign in this closed circuit, and in order to adjust the amout of this compensating voltage an automatic control device using a negative feedback was employed here. As is shown in fig. $2(a)$, the input signal $E_{i}$ is received by an input cathode follower with the microelectrode of resistance $R_{e}$ and is amplified by a direct coupled amplifier of gain $G$, the output voltage of which $\left(E_{0}\right)$ is fed back between Ringer bath and the earth by a phase-inverting circuit with a transfer function of $H$. The relationship between $E_{i}$ and $E_{0}$ is expressed by the following equation,

$$
E_{0}=E_{i} k G /(1+k G H),
$$

where $k=R_{s} /\left(R_{s}+R_{e}\right)$. For the compensating voltage $E_{c}$ appearing between Ringer bath and the earth,

$$
\begin{aligned}
E_{c} & =-E_{0} H \\
& =-E_{i} k G H /(1+k G H) .
\end{aligned}
$$

Therefore the difference between $E_{i}$ and $E_{c}$ is equel to $E_{i} /(1+k G H)$, and the effect of $E_{i}$ in the stimulating circuit is reduced to $1 /(1+k G H)$ of the original value. When $G$ is $120, H 1$ and $R_{e} 30 \mathrm{M} \Omega$, the value of $1 /(1+k G H)$ is $1 / 91$, which could be sufficient for the present purpose.

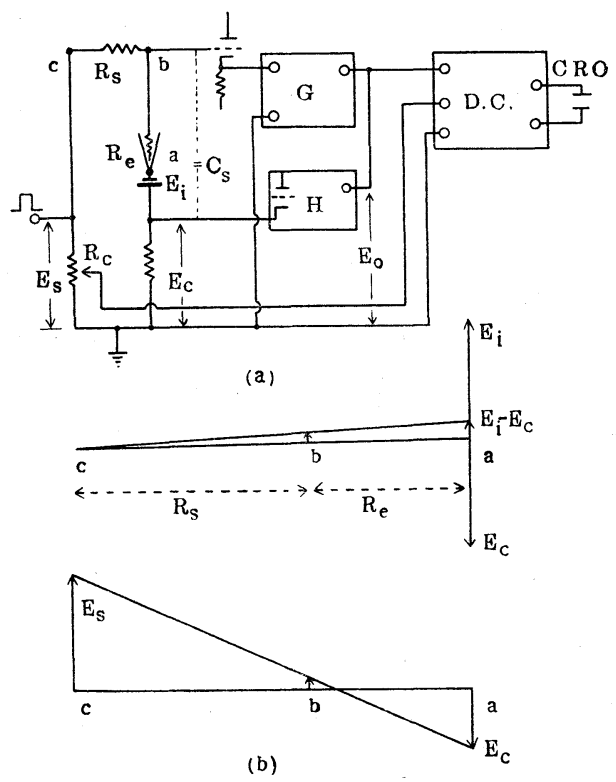

FIG. 2. (a) Principle of the automatic compensation of the membrane potential. $E_{i}$; electromotive force originated from the cell membrane, $E_{c}$; the one to be inserted to compensate $E_{i}, E_{0}$; output of the preamplifier, $E_{s}$; stimulating voltage, $G$; two-stage direct coupled amplifier, $H$; negative feedback loop, D.C.; main d.c. amplifier, $C_{s}$; capacity across the wall of the microelectrode. (b) Relationship among $E_{i}, E_{c}$ and $E_{s}$. The potential changes in three points, which are marked as $a, b$ and $c$ in $(a)$, are shown by arrows. Upper diagram; compensation for the true input signal. Lower diagram; for the stimulating pulse.

On the other hand, when the stimulating voltage $E_{s}$ is introduced through $R_{s}$, the corresponding values of $E_{0}$ and $E_{c}$ are obtained as follows;

$$
E_{0}=E_{s}(1-k) G /(1+k G H),
$$




$$
E_{c}=-E_{s}(1-k) G H /(1+k G H) .
$$

As is shown in fig. $2(b)$, the grid of the input cathode follower is maintained near zero potential level by $E_{c}$, and the current $I_{s}$ flowing through $R_{s}$ is;

$$
\begin{aligned}
I_{s} & =\left(E_{s}-E_{c}\right) /\left(R_{s}+R_{e}\right) \\
& =\frac{E_{s}}{R_{S}}\left(1-\frac{1-k}{1+k G H}\right) .
\end{aligned}
$$

Consequently $I_{s}$ is almost equal to $E_{s} / R_{s}$ with the error of $(1-k) /(1+k G H)$, which is as small as $1 / 440$ if it is calculated with the same values as above, and therefore the stimulating current can be estimated by measuring the stimulating voltage regardless the resistance value of the microelectrode.

The output voltage, caused by the stimulating wave and shown in the equation (3), is compensated by introducing the same potential wave through $R_{c}$ into one of the differential inputs of the main d.c. amplifier with a large inphase rejection ratio of 20,000 (fig. $2(a)$ ), and by this method the same results can be obtained as that got by a bridge circuit. By reading the position of $R_{c}$ adjustor, where this compensation is correctly achieved, the electrode resistance can be measured at any time during the experiments, if it is calibrated previously by the resistors of known values inserted in the input circuit in place of Re.

This preamplifier has another advantage in improving the frequency characteristics of the input stage by the negative feedback, when a high resistance microelectrode is used. Since the input stage of the cathode follower type was used by Nastuk and Hodgkin (1950) in order to reduce the input capacitance, several devices have been adopted to obtain high fidelity of the input stage (Solms et al., 1953; Haapanen and Ottoson, 1954; MacNichol, 1954) by minimizing the capacitance between the grid and cathode, and by cancelling the one existing across the wall of microelectrode. In the present circuit the high gain of the amplifier $G$ is effective for the former purpose and the latter is accomplished by adjusting the magnitude of the negative feedback. When there exists a capacity across the wall of the microelectrode between Ringer bath and the grid of the input cathode follower, the factor $k$ has a different value $\left(k_{1}\right)$ for receiving an input signal $E_{i}$ of high frequency from that $\left(k_{2}\right)$ for $E_{c}$, the compensating voltage of $E_{i}$, because this capacity is inserted in parallel with $R_{s}$ for receiving $E_{i}$ while it is in parallel with $R_{e}$ for $E_{c}$ (fig. $2(a)$ ). Therefore the equation (1) should be modified to,

$$
E_{0}=E_{i} k_{1} G /\left(1+k_{2} G H\right) .
$$

When the frequency of the input signal increases, $k_{1}$ is reduced, while $k_{2}$ is augmented. Both of them decrease the output voltage $E_{0}$, but according to the above equation, this can be cancelled by reducing the value of $H$.

The actual circuit of the preamplifier is shown in fig. 3. The input cathode follower $12 \mathrm{AU} 7\left(V_{1}, V_{2}\right)$ (Tomita and Torihama, 1956) was used in the cascade form (Solms et al., 1953), by which the grid current as low as $1 \times 10^{-12}$ A could be easily obtained. For $G$ amplifier a two-stage direct coupled amplifier of 


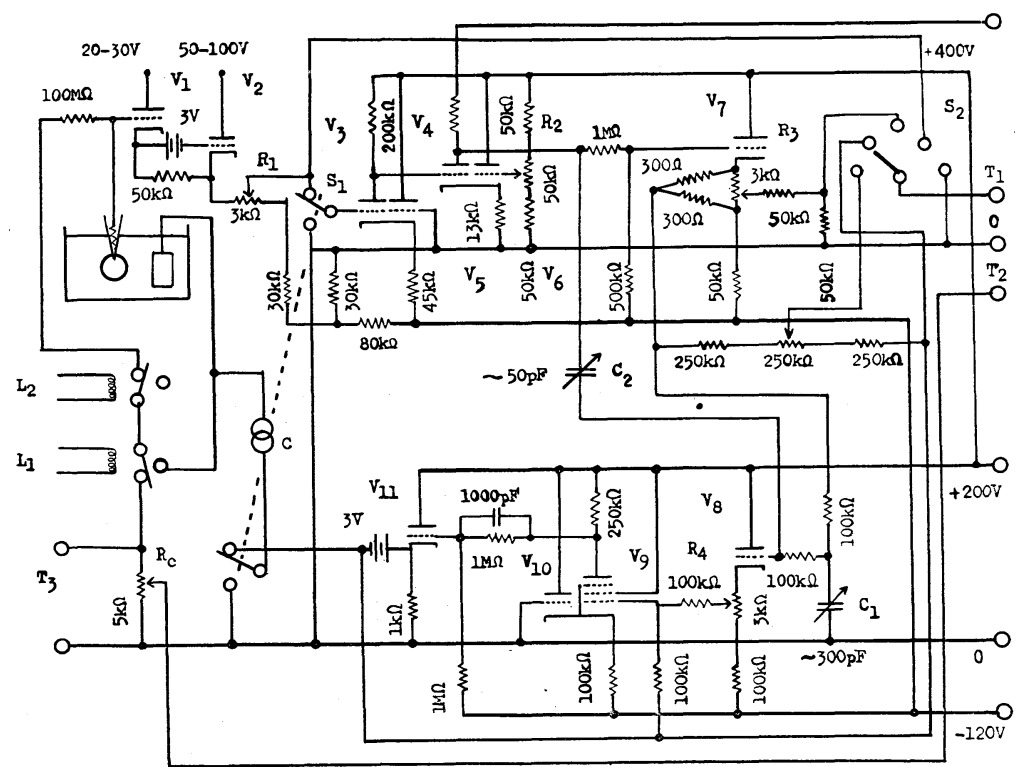

FIG. 3. Circuit diagram of the preamplifier. $V_{1}, V_{2}, V_{7}, V_{8}, V_{10}, V_{11} ; 12 \mathrm{AU} 7$ 's, $V_{3}, V_{4} ; 12 \mathrm{AX} 7, V_{5}, V_{6} ; 12 \mathrm{AT} 7, V_{9} ; 6 \mathrm{AU} 6, C$; calibrator. $T_{1}$ and $T_{2}$ were connected to differential inputs of the main d.c. amplifier and $T_{3}$ was to a pulse generator.

Miller's type (1941) was used $\left(V_{3}, V_{4}, V_{5}, V_{6}\right)$, and the mean d.c. level of its output was kept at the zero potential level by a cathode follower $\left(V_{7}\right)$. The negative feedback loop was composed of an input cathode follower for frequency compensation $\left(V_{8}\right)$, a phase-inverting stage $\left(V_{9}, V_{10}\right)$ and an output cathode follower $\left(V_{11}\right)$. Because the Ringer bath was connected to the cathode of $V_{11}$ through dry batteries of $3 \mathrm{~V}$, the compensating voltage of negative sign was limited within $-3 \mathrm{~V}$, and the direct stimulating current was also limited within $1 \times 10^{-7} \mathrm{~A}$ when the electrode resistance was $30 \mathrm{M} \Omega$. The high frequency response of this preamplifier was tested by introducing a square pulse through $R_{s}$ while putting the microelectrode tip near a cell (Solms et al., 1953), and the suitable response was obtained by adjusting the variable condensers $C_{1}$ and $C_{2}$. As is shown in fig. $4(A)$, the input time-constant remained usually within 20-60 $\mu$ sec even when the electrode resistance was as high as 30-70 $\mathrm{M} \Omega$.

In order to check the working conditions of the whole preamplifier, the following 4 points were observed by using selector switches $S_{1}$ and $S_{2}$; (1) the output of the input cathode follower with the negative feedback loop off, where the Ringer bath was connected directly to the earth, (2) the same with the loop on, (3) the output of $H$ circuit and (4) the point obtained in the divider chain mixing $E_{0}$ and $E_{c}$ in the ratio of $1 / H$. Before the microelectrode was touched to the Ringer bath, $R_{s}$ was inserted in place of the eletrode by the aid of relay $L_{1}$, and all of points (1)-(4) should be adjusted to the zero potential level, using $R_{1}$ for (1), $R_{2}$ for (2) and $R_{4}$ for (4) successively, and finally the output voltage of the preamplifier was controlled by $R_{3}$. 

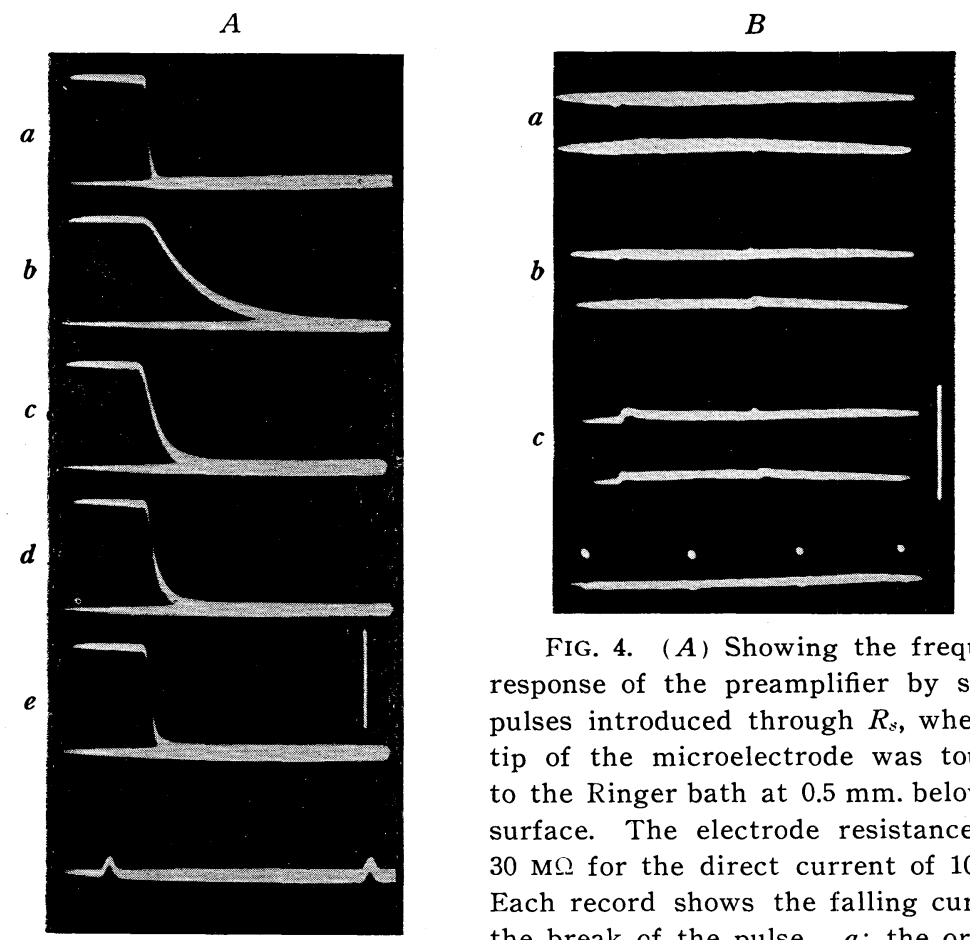

FIG. 4. ( $A$ ) Showing the frequency response of the preamplifier by square pulses introduced through $R_{s}$, when the tip of the microelectrode was touched to the Ringer bath at $0.5 \mathrm{~mm}$. below the surface. The electrode resistance was $30 \mathrm{M} \Omega$ for the direct current of $10^{-9} \mathrm{~A}$. Each record shows the falling curve at the break of the pulse. $a$; the original pulse recorded through $R_{c} . \quad b$; recorded by the ordinary cathode follower input stage with the negative feedback loop off. The input capacitance was $5.7 \mu \mu \mathrm{F}$. $c$ and $d$; compensated recording. Input capacitance was $1.3 \mu \mu \mathrm{F}$ in $c$ and 0.8 $\mu \mu \mathrm{F}$ in $d, e$; slightly overcompensated. Voltage scale; $50 \mathrm{mV}$. Time marker; $1 \mathrm{msec}$.

( $B$ ) Electrical resistance of a microelectrode for direct currents. The resistance value was $60 \mathrm{M} \Omega$ for the alternating current of $10^{-7} \mathrm{~A}$ and $28 \mathrm{M} \Omega$ for the direct current of $10^{-9} \mathrm{~A}$. Each record was obtained by the electrode tip being touched to Ringer solution and by cathodal (upper trace) and anodal (lower trace) square pulses introduced through $R_{s}, R_{c}$ was adjusted for each current. Current strength: $a ; 1 \times 10^{-9} \mathrm{~A}, b ; 3 \times 10^{-9} \mathrm{~A}, c ; 5 \times 10^{-9} \mathrm{~A}$. Voltage calibration; $50 \mathrm{mV}$. Time marker; $100 \mathrm{msec}$. All records are represented with positivity upwards.

Drift is the most important problem in using such instruments. For the drifts of either the input cathode follower or $G$ amplifier the negative feedback loop behaved in the same way as for the true input signal, and consequently potentials corresponding to these drifts appeared in $E_{c}$, from which an injurious current flowed through the cell membrane. To avoid this the following procedures were employed. A relay $L_{2}$ was inserted to open the stimulating circuit during the experiments. If $R_{s}$ was detached from the output terminal of the stimulator, the factor $k$ changed to 1 , while the equation (1) shows that in spite of this change the output voltage of the preamplifier for the true input signal was kept at the same value within a minute error. On the other hand 
with an erroneous input signal $E_{d}$ caused by the drift the output voltage has following relation;

$$
E_{0}=E_{d} G /(1+k G H),
$$

which tells that $E_{0}$ changed when the stimulating circuit was opened by relay $L_{2}$. Therefore, the drifts in these stages could be eliminated by adjusting $R_{2}$ to an appropriate position where the opening of the stimulating circuit by $L_{2}$ did not cause any change in the output voltage. A special relay having small stray capacity and good insulation was used as $L_{2}$. Drift occurred also in $H$ circuit, which, however, hardly produced deviations in $E_{\varsigma}$, but it introduced errors in $E_{0}$. In order to avoid these errors, the point (4) was watched during the experiment and, when it deviated from the zero potential level, $R_{4}$ was readjusted to cancel this deviation, because, unless drift took place in $H$ circuit, $E_{c}$ was equal to $-E_{0} H$ and consequently, the point (4) did never deviate from the zero potential level. These drifts were usually less than $5 \mathrm{mV}$ during 1 hour, when power supplies for both low and high tensions were derived from the commercial A.C. source.

The gain of this preamplifier did not depend upon the electrode resistance in contrast to the simple bridge method, because it was always almost equal to $1 / H$ as is shown by equation (1). The actual value of $H$ was 0.6 , and therefore the gain was about 1.6, which was, however, reduced approximately to 1 by a divider chain (fig. 3) for convenience in practice. The noise level was usually within $0.5-1.0 \mathrm{mV}$. using microelectrodes of $30-70 \mathrm{M} \Omega$, when it was suitably compensated for high frequency response.

Recording and stimulating equipments. Two cathode ray tubes of a single beam were used for recording and photographed in the same frame by the aid of mirrors. Each beam of these was chopped to double traces by a monitor oscillator of $20 \mathrm{kc} / \mathrm{s}$, though they were photographed one by one during two successive sweeps. Each tube had an independent time base, the first one of which swept at low velocity and was locked to a dual-channel pulse generator, and the second one was triaggered by one of the stimulating pulses and showed detailed features of action potentials by fast sweep. The output of the main d.c. amplifier was modulated by a thyratron oscillator (Draper and Weidman, 1951), which drived a speaker, and the d.c. potential level was heard by pitch of the sound. For the output stage of the stimulator a radio-frequency isolator (Schmitt and Dubbert, 1949) was employed.

Microelectrodes. They were pulled from a glass tubing by a mechanical instrument and filled with $3 \mathrm{M}-\mathrm{KCl}$ solution by alcohol method (Tasaki et al., 1954). The shape of their tip was very critical for successful impalements and gradually tapered and sharp ones were preferred. Electrode resistance was first measured by alternating current of $10^{-7} \mathrm{~A}$ and those with resistance of more than $70 \mathrm{M} \Omega$ or less than $30 \mathrm{M} \Omega$ were rejected. The electrodes of lower resistance than $20 \mathrm{M} \Omega$ were apt to cause serious injuries of the cell membrane, though they could penetrated it more easily. In order to accomplish correct 
compensation of the potential drops caused by current flows through the microelectrode, the linearity of its resistance was demanded. As was described by Jenerick and Gerard (1953), the microelectrode resistance was different to some extent for the current of opposite direction and, moreover, the linearity became worse with increasing the currents. The microelectrodes selected as above usually showed lower resistivity by $10-30 \mathrm{M} \Omega$ for the direct current of $10^{-9} \mathrm{~A}$ than for the alternating current of $10^{-7} \mathrm{~A}$, and for the cathodal current (outflowing from the tip) their resistance was usually higher by several $M \Omega$ than for the anodal one. As is shown in fig. $4(B)$, they behaved in almost all cases as non-linear resistors for the current stronger than $5 \times 10^{-9} \mathrm{~A}$, while for the current less than $2-3 \times 10^{-9}$ A about $60 \%$ of them were fit for use.

Because the value of electrode resistance changed with incresing the current strength or with the change of the current direction, the position of $R_{c}$ should be readjusted for each polarising current during impalements. However, the time-constant of the polarised potential of the cell membrane was much larger than that of the potential change due to electrode resistance, so that this readjustment was achieved without large errors when electrodes were well selected and the current strength was less than $2 \times 10^{-9} \mathrm{~A}$.

The experiments were usually carried out in room temperatures of $9-18^{\circ} \mathrm{C}$. and higher temperatures more than $15^{\circ} \mathrm{C}$. were obtained in winter by warming the shielded room. No attempt has been made to supply oxygen gas for ganglions, because the cells on the surface layer of the ganglion was in contact with the air through a thin layer of Ringer solution and no signs of anoxia could be detected even 10 hours after dissection. The Ringer solution contained $\mathrm{NaCl} 6.5, \mathrm{KCl} 0.2, \mathrm{CaCl}_{2} 0.2$ and $\mathrm{NaHCO}_{3} 0.2 \mathrm{~g} / 1$.

RESULTS

\section{A. Impalements of the ganglion cells}

In general the impalement was carried out both with a single shock of duration $50 \mu \mathrm{sec}$. applied to the peripheral nerve and with an anodally polarising current of duration about $100 \mathrm{msec}$. and intensity $1 \times 10^{-9} \mathrm{~A}$ through the microelectrode, which were given during each sweep of the time-base repeating once per 1-3 seconds (fig. 5). When the microelectrode was moved forward to the centre of the cell image, there appeared usually positive potential deflections amounting $10-30 \mathrm{mV}$ (fig. $5(a)$ ), which might be due to touching of the electrode tip on the loose connective tissue or the cell capsule (Lenhossék, 1886), because the polarising current always showed a large increase in electrical resistance of the electrode tip. This potential deflection can not be explained as the potential drop caused by the grid current flowing through the increased electrode resistance, because the grid leakage was always kept at the value less than $100 \mathrm{M} \Omega$ by $R_{s}$. Moreover, negative defiections could appear in the same situation as above when the proper resistance of the electrode was low or reduced during the experiments. This negative deflection amounted to $10-$ $70 \mathrm{mV}$ and was very mistakable for the real resting potential of the cell membrane, though it could be distinguished from the latter by both the gradual 


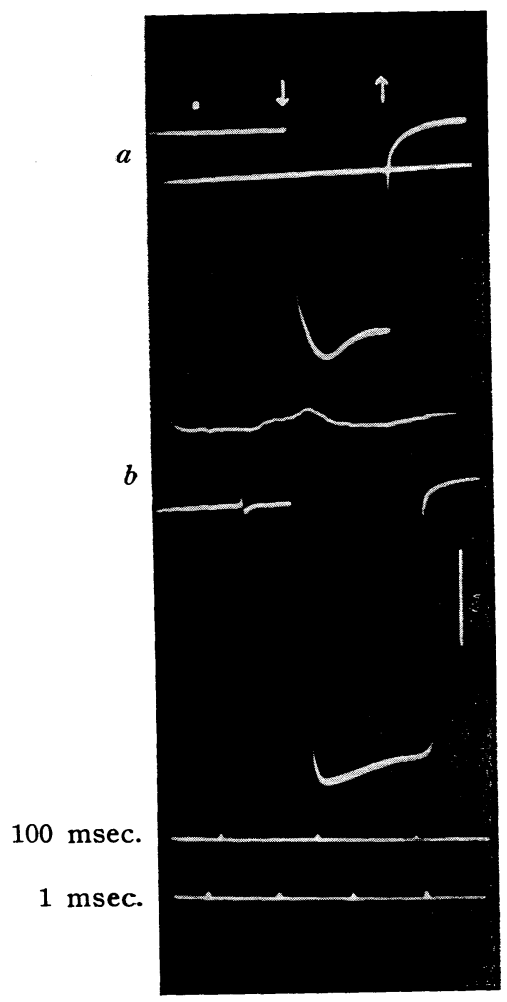

FIG. 5. Potential changes detected by the microelectrode tip before it penetrated the cell membrane. An indirect stimulus applied to the peripheral nerve is marked by a dot and the onset and cessation of an anodally polarising current are shown by arrows. $a$; positive potential deflection taking place when the electrode approached the cell, where the polarising current could show a large increase of the electrical resistance in the electrode tip (uppermost trace). Second trace shows the zero potential level, which was obtained when the electrode was pulled back from the cell. $b$; an extracellularly recorded action potential of the spinal ganglion .cell. Upper trace was obtained by the second oscilloscope, the time base of which was triggered by the indirect stimulus. Time signal of 1 msec. is for the upper trace of $b$ and that of $100 \mathrm{msec}$. for the lower one. Voltage calibration; $50 \mathrm{mV}$.

potential change following the movement of the electrode tip and the augmentation of the tip resistance, which usually showed irregular and sometimes oscillatory nature for the polarising current in contrast to the real polarised potential of the cell membrane. These kinds of potentials could be produced by touching the electrode tip either on the connective tissue or on the cotton fiber under the direct microscopical control, and when the electrode resistance was higher, positive deflections took place more easily. The tip of the microelectrode is known to have a junctional potential (Adrian, 1956) and the potential change described above might be due to a physical process occuring in the electrode tip (cf. Svaetichin, 1956). The reason why there appeared positive potentials in electrodes of higher resistance and negative deflections in those of lower resistance is not clear in the pressent stage, but this difference seemed to depend upon the size of the tip diameter. The electrodes showing negative deflections were rejected, because good results could hardly be obtained by them. When such a potential deflection was observed, the action potential of the ganglion cell could often be recorded extracellularly, which usually showed a diphasic configuration (fig. $5(b)$ ). Because it was considerably difficult to penetrate through the connective tissue dispersed arround the cell, the microelectrode was moved forward carefully, observing the positive potential deflection and, if it failed to impale the cell, the electrode was pulled back and the 
penetration was attempted repeatedly. If the electrode impaled the cell membrane successfully, the resting potential appeared suddenly, which usually ranged from 50 to $80 \mathrm{mV}$.

The procedure to impale the cell applying both indirect stimuli to the nerve and hyperpolarising currents to the cell membrane was greatly useful to see whether the cell membrane was in good conditions or injured by the penetration. Fig. $6(a)$ and $(b)$ show the commonest features of the response in the impaled cell, in which small action potentials of long durtion were evoked indirectly and the anodal break excitation occurred. Even when the action potential was large immediately after the pentration, it usually deteriorated to the same state as above within a few minutes. In this circumstance it was necessary to readjust the position of the electrode tip, usually to pull it back little by little. If this procedure was successful, the anodal break excitation ceased (fig. $6(c),(d)$ ), and even the local response being observed after the break of the anodal current disappeared $(e)$, and also the polarised potential of the cell membrane increased indicating the augmentation of the membrane resistance. In company with these changes the resting potential increased and the action potentials evoked by indirect stimulations became large in magnitude and short in duration. The reason why the readjustment of the electrode position was so successful to improve conditions of the cell membrane might be explained as follows: The forced penetration against the resistance of the connective

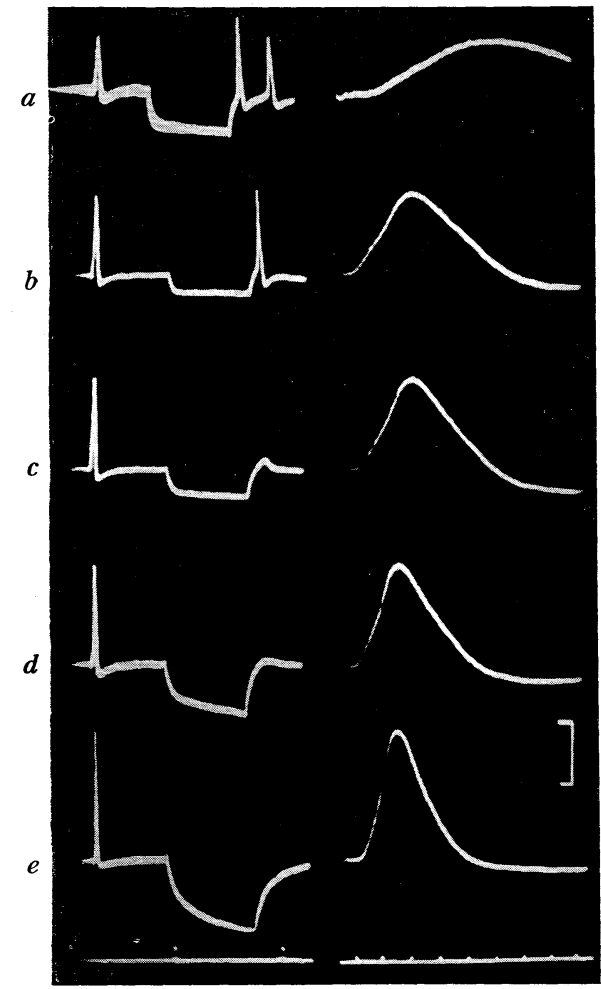

FIG. 6. Photographs showing the recovering of the cell responses by readjustment of the electrode position after impalement. The microlectrode was pulled back little by little and the response of the impaled cell recovered from $a$ to $e$ during 2 minutes. Cell diameter $60 \mu, 10^{\circ} \mathrm{C}$. Left photographs were taken by the first oscilloscope, and after the peripheral nerve was stimulated an anodal pulse of $1 \times 10^{-9}$ A was applied to the cell membrane as in fig. 5. Right ones were taken by the second oscilloscope, the time base of which was triggered by indirect stimuli. Voltage scale; $50 \mathrm{mV}$. Time markers: left; $100 \mathrm{msec}$., right; $1 \mathrm{msec}$. Photographs taken by the first oscilloscope with slow sweep velocity have been retouched in this as well as in the subsequent figures. 
tissue and the cell capsule would have caused the deformation of the cell membrane, and would have inserted the electrode tip deeply into the cell, and therefore, when the electrode was pulled back slightly, the extended cell membrane could have recovered to the normal state and resealed arround the electrode tip. The fact that the electrode position, where the best response was obtained as in fig. $6(e)$, was usually lost by a further minute withdrawal, could support this explanation. There were few cases, in which impalements were so successful that the good condition lasted for a long time without any readjustment of the electrode position. On the other hand, when this readjustment was well accomplished, the cell response could be observed during 1-5 hours without suffering from any deterioration.

In order to make easier the impalements some enzymes were used to soften the connective tissue by Eyzaguirre and Kuffler (1955 a), which were not tested in the present experiments. There was considerable variety in the quantity of the connective tissue depending upon the conditions of toads, though it was difficult to determine what these conditions were. However, several cells suitable for the successful impalements could usually be obtained from each preparation.

The spinal ganglion cells of toads usually have a spherical or oval shape and have a maximum diameter of 90-30 $\mu$. Because it was difficult to impale successfully the cells with a diameter less than $60 \mu$, the description of the section $(B)-(F)$ deals only with results obtained in large cells with a diameter more than $60 \mu$, which could be considered to be connected to myelinated axons (Lenhossék, 1886).

\section{B. Resting and action potentials}

A typical example of the action potential evoked by indirect stimulation is shown in fig. 7 . No differences could be found between the action potential evoked by the stimulation of the peripheral nerve and that obtained by dorsal root stimulation. The resting and action potentials obtained from 50 cells, which could be judged by the criterion described above to be without injury, are summerized in fig. 8 . These results show a considerable scattering arround the value of the resting potential of $65 \mathrm{mV}$ and of the action potential of 100 $\mathrm{mV}$. The maximum value so far obtained is $83 \mathrm{mV}$ in the former and $125 \mathrm{mV}$ in the latter. The overshoot of the action potential sometimes amounted to 50 $\mathrm{mV}$ ( $\max .57 \mathrm{mV}$ ), but for the correct estimation of these values the errors introduced by the junctional potential of the microelectrode should be taken into consideration.

The duration of the action potential, i.e., time from the foot of its rising phase to the point, where its falling phase crossed the base line, was 1.2-4.1 msec. (mean of 25 cells, $2.8 \mathrm{msec}$.) at $15-20^{\circ} \mathrm{C}$. The maximum rate of rise ranged from 170 to $455 \mathrm{~V} / \mathrm{sec}$. (mean of the same examples as above, 319 $\mathrm{V} / \mathrm{sec}$.), and that of fall was between 58 and $275 \mathrm{~V} / \mathrm{sec}$. (mean, $161 \mathrm{~V} / \mathrm{sec}$.).

As is shown in fig. 7 , the rising phase of the action potential had two inflection points $N_{1}$ and $N_{2}$ at $4.2-7.6 \mathrm{mV}$ and $32-58 \mathrm{mV}$ from the resting level. The rise time of $N_{1}$ was $0.1-0.2 \mathrm{msec}$. and the time from $N_{1}$ to $N_{2}$ was $0.2-0.9$ 


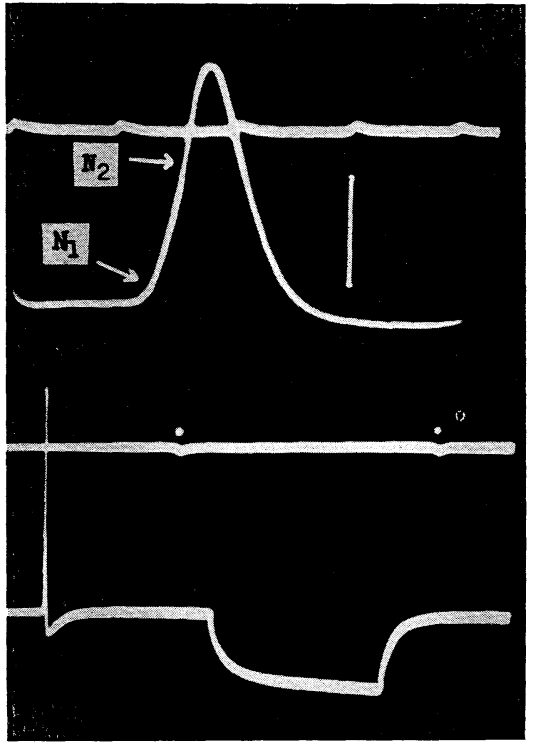

FIG. 7

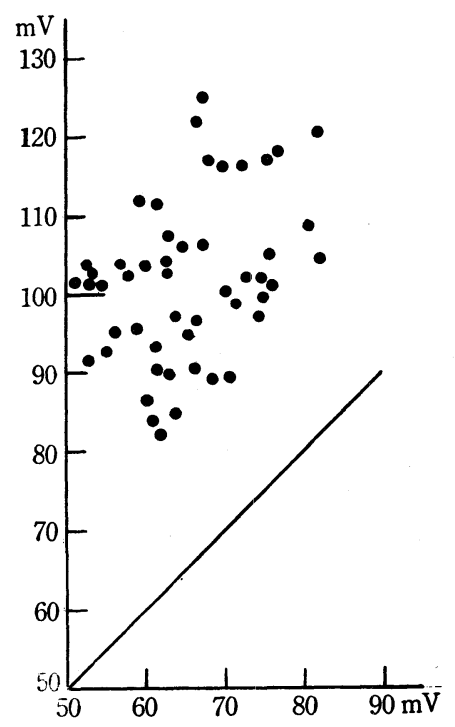

FIG. 8

FIG. 7. A typical example of the action potential of the spinal ganglion cell, evoked indirectly by the peripheral nerve stimulation. Upper and lower photographs were taken simultaneously in the same way as in fig. 6. The rising phase of the action potential had two inflection points $\left(N_{1}\right.$ and $\left.N_{2}\right)$. Voltage scale $50 \mathrm{mV}$ for the upper record. Time markers; $1 \mathrm{msec}$. in the upper record and $100 \mathrm{msec}$. in the lower one, which were superposed on the zero potential level. Cell size; $90 \mu, 18^{\circ} \mathrm{C}$.

FIG. 8. Resting and action potentials recorded from 50 cells. Ordinate; magnitude of the action potential. Abscissa; resting potential.

msec. at $15-20^{\circ} \mathrm{C}$. These inflection points could indicate the superposition of three potentials of different nature.

Brock, Coombs and Eccles (1953) found three component potentials in the action potential of cats' motoneurones activated antidromically, which were named as SD spike, NM spike and $\mathrm{M}$ spike indicating their origination from the cell body and dendrites, the non-myelinated segment and the axon respectively. By the analysis of the spike configuration both under the hyperpolarisation and during the refractory period the two inflection points of the action potential of toads' spinal ganglion cells were confirmed to be due to the superposition of three component potentials corresponding to those of cats' motoneurones. Because the sites of origination of these three potentials were proved to be the cell body, which has no dendrites (Lenhossek, 1886), the non-myelinated segment and the node or nodes of Ranvier in axon (Ito; Ito and Saiga, in manuscript), it should be reasonable to call them S spike, NM spike and M spike respectively. Recently Eccles (1957) adopted the name of IS spike in place of NM spike, because the initial segment, which includes both the non-myelinated segment and the axon hillock, should be considered to be 
the site of its origination. However, in the spinal ganglion cells of toads the corresponding component potential could be originated only from the nonmyelinated segment, and the name of NM spike was adopted here (Ito, in manuscript).

When the membrane resistance was low, which told that the electrode tip could not have been resealed successfully, the cell response usually deteriorated from S-NM-M complex to NM-M complex (fig. $9(a)$ ) and further to small M spike $(b)$. If the response once deteriorated to $\mathrm{M}$ spike, the immprovement by the readjustment of the electrode position could not usually be expected.
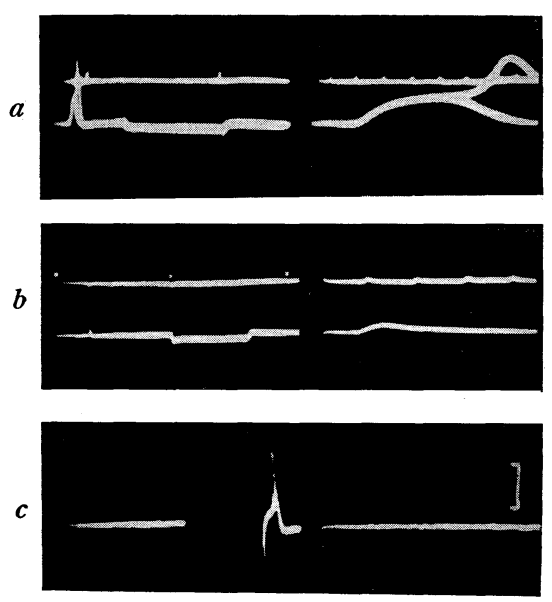

FIG. 9. Responses of injured cell membranes. Strength of the anodal current was $1 \times 10^{-9} \mathrm{~A}$ in $a$ and $b$, and $2 \times 10^{-8} \mathrm{~A}$ in $c, a$; NM spike and $S$ spike under the critical condition for block. Two successive sweeps were superimposed. $b$; M spike. $c$; severely damaged membrane. Voltage calibration; $50 \mathrm{mV}$. Time markers: left; 100 msec., right; $1 \mathrm{msec}$. Photographs are arranged as in fig. 6.

There is shown in fig. 9 (c) a strikingly damaged state of the cell membrane, in which the nerve stimulation could never evoke any response in spite of the existence of a fairly stable resting potential. In such cases even the direct stimulation by a cathodal current failed to excite the cell membrane, but break excitation could occur by a strong anodal pulse.

\section{After-positivity}

The termination of the falling phase of the action potential was succeeded by an after-positivity (hyperpolarisation from the resting level) of 1-6 $\mathrm{mV}$ in magnitude and of 5-22 msec. in duration, which reached the maximum value within $0.2-4.0 \mathrm{msec}$. after crossing the resting level. This hyperpolarisation may be of the similar nature to that described as positive dip in toads' motoneurones (Araki and Otani, 1955), as after-positivity in stretch receptor cells of crayfish (Eyzaguirre and Kuffler, $1955 \mathrm{~b}$ ) or as post-spike hyperpolarisation in spinal ganglion cells of cultured chick embryo (Crain, 1956). The magnitude and the time-course of this after-positivity could be changed by the polarising current, i.e., under the hyperpolarised state it became smaller and with the further increase of the current it inverted into after-negativity, while by the depolarisation it became faster in its time-course (fig. 10). As is shown in fig. 11, its magnitude changed in almost linear relation to the alteration of the membrane potential with the slope of unity $(0.89,1.06$ and 1.07 , as measured in three 


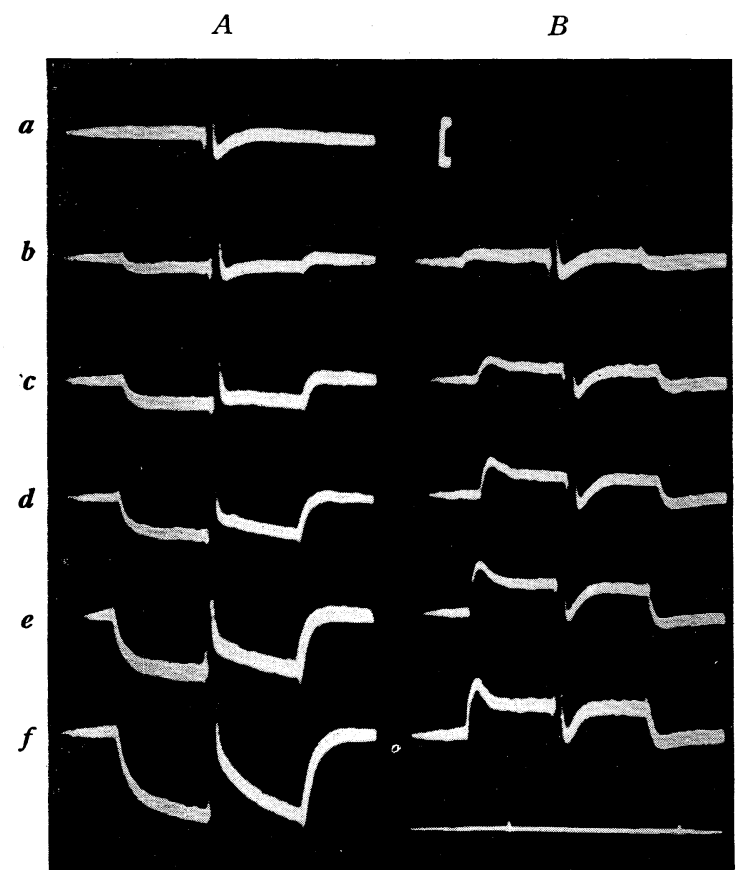

FIG. 10. After-positivity under various membrane potential. Action potentials, upper parts of which were cut off, were evoked by indirect stimulation during the course of both hyperpolarisation $(A)$ and depolarisation $(B)$. Current strength: $b$; $1, c ; 3, d ; 5, e ; 7$ and $f ; 9 \times 10^{-10}$ A. Voltage scale; $10 \mathrm{mV}$. Time marker; $100 \mathrm{msec}$.

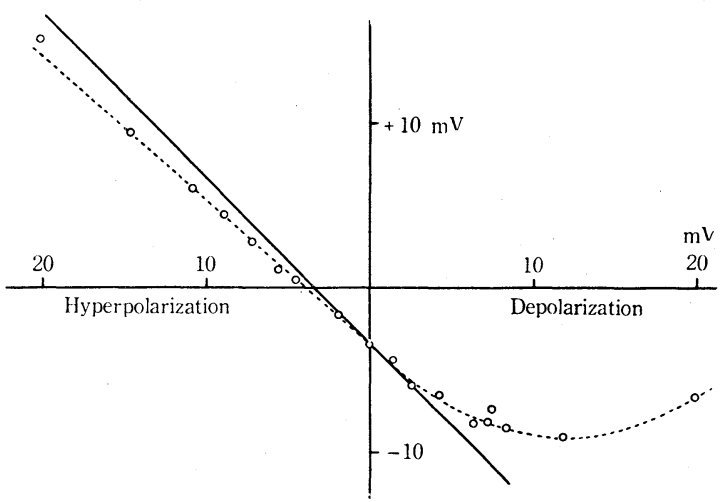

FIG. 11. Relationship between the magnitude of the after-positivity (ordinate) and the altered value of the membrane potential (abscissa), obtained from records of fig. 10 . Negative sign shows the after-positivity and positive one the after-negativity. Straight line indicates the slope of unity. examples) under the hyperpolarisation, but under the depolarisation it deviated strikingly from this line. The measurement of the potential level, where the after-positivity became zero, was not attempted, because the value of the resting potential was too scattered, as is described in section (B), to give an accurate data.

It was, however, sometimes noticed that the resting potential was so large that the faling phase of the action potential was followed by an after-negativity without any hyperpolarising current, but such a large resting potential could only be observed during a short time, and the slightly lowered level, where the after-positivity appeared, was obtained usually in the impaled cell membrane. On the other hand when the cell response had once deteriorated to a small NM spike and it had taken a long time (10-20 minutes) to improve it, the action potential often accompanied an after-negativity, although the resting potential was low, but this was usually inverted into an after-positivity by a further recovery taking place during next 10-30 minutes.

The after-negativity, which was observed either with a hyperpolarising current or without it, often showed a slow hump in its falling phase (fig. $10(c)$ ), which could be apparently distinguished from the local response being observed under the injured state. As is shown in fig. 12 , the after-positivity behaved in the same way as an 


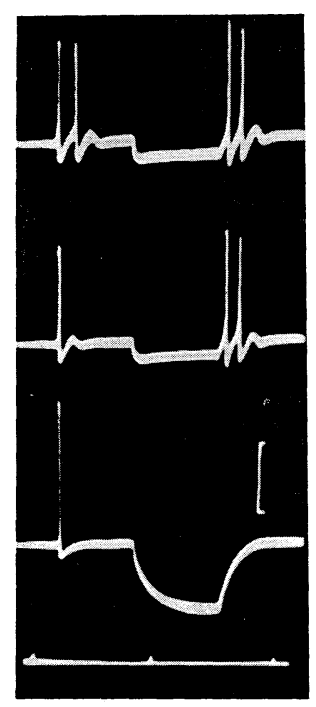

FIG. 12. Repetitive responses under the injury. $a$; double firing evoked by both a single indirect stimus and break of an anodal pulse. $b$; second response for the indirect stimulus was ceased, leaving a local response. Response of the membrane recovered to $c$ after 4 minutes following the same course as is shown in fig. 6. Cell diameter; $80 \mu, 20^{\circ} \mathrm{C}$. Voltage calibration; 50 $\mathrm{mV}$. Time marker; $100 \mathrm{msec}$.

anodal pulse in the sense that it produced the break excitation, and sometimes double or tripple responses took place to a single shock applied to the nerve. Such repetitive responses were observable especially often in spring or in warmed preparations even during winter. However, because such responses did never occur under the normal condition (fig. $12(c)$ ), it might have been caused by an injury just like by a strong cathodal current (fig. 13) (cf. Coombs et al., 1955 a).

In a few cases the impalements caused continuous bursts of the impulses without any stimuli, which usually lasted for several minutes and ceased finally after the action potentials deteriorated to NM spike or $M$ spike, but the readjustment of the electrode position could often succeeded to stop such a spontaneous firing and to obtain ordinary responses.

The time-course of the after-positivity was usually slower than that of the passive discharge of an anodal polarisation, which was caused by a short pulse of duration less than $1 \mathrm{msec}$. and of a suitable intensity for giving a similar polarisation to the after-positivity. This difference was most remarkable in the strychnized cell, where the duration of the after-positivity prolonged to several hundred milliseconds while the polarised potential caused by an extrinsic current followed nearly the same time-course as in the normal Ringer solution (Ito and Saiga, in manuscript).

\section{Direct stimulation of the cell membrane}

As can be seen in fig. 13, at the initial phase of the depolarisation a local response was observed and, when it reached a critical level, the cell membrane generated the action potential as was observed in giant axon (Hodgkin, 1938), in muscle fiber (Katz, 1937) or in spinal motoneurones (Aarki and Otani, 1953; Coombs et al., $1955 \mathrm{a}$; Frank and Fuortes, 1956). The rheobasic current for the cell membrane ranged from 0.6 to $2.2 \times 10^{-9} \mathrm{~A}$ (mean of 17 cells, $1.2 \times 10^{-9} \mathrm{~A}$ ) and the critical depolarisation for the initiation of the action potential was between 13.7 and $23.0 \mathrm{mV}$ (mean of the same examples as above, $17.0 \mathrm{mV}$ ). When a rectangular pulse of a short duration was applied, the local response and the action potential occurred after the break of the current (fig. $13(c)$ ), by which the strength-duration curve was plotted in fig. 14 (see the section $(E)$ ).

It was of interest to find that the action potential evoked by the direct 


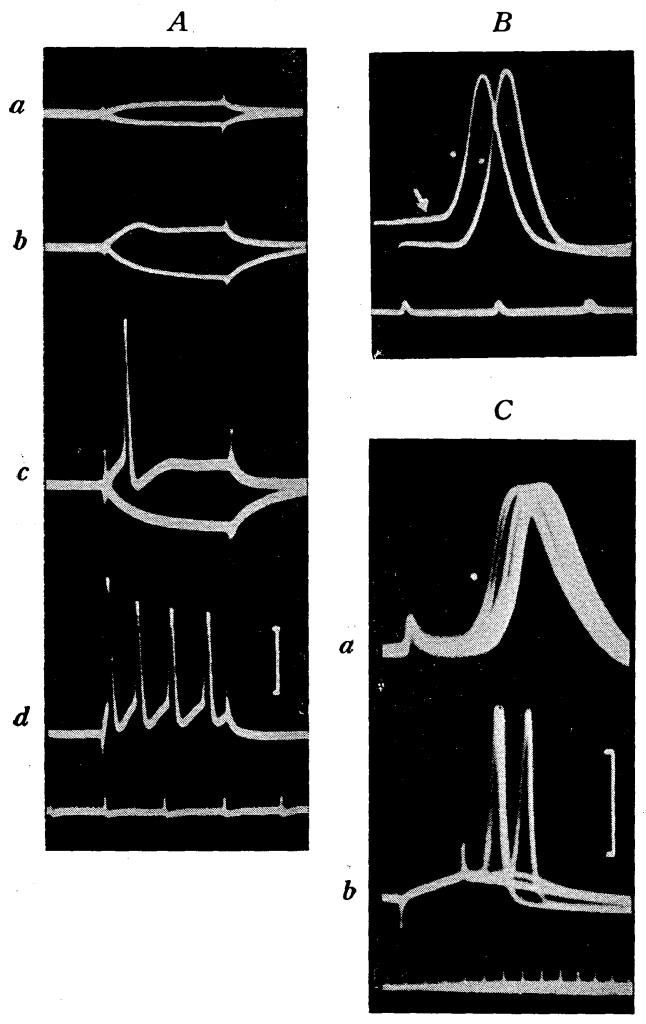

FIG. 13. Responses of the cell membrane to direct stimulating currents.

(A) Polarisation by both cathodal and anodal currents of $20 \mathrm{msec}$. duration. Current strength: $a ; 3, b ; 6, c$; $10, d ; 25 \times 10^{-10} \mathrm{~A}$. Voltage sacle; 50 $\mathrm{mV}$. Time marker; $10 \mathrm{msec}$. Cell diameter; $80 \mu, 20^{\circ} \mathrm{C}$. in April.

(B) An action potential evoked directly by the rheobasic current (arrow) is superimposed with the one evoked by an indirect stimulus. Initial part of the rising phase of the depolarisation is omitted from the figure. The magnitude of the action potential evoked directly was smaller than that of the indirectly evoked one, but the rising phase of the action potential had the second inflection point in both cases (marked by dots). Time marker; $1 \mathrm{msec}$. Amplification was nearly the same as in $(A)$.

(C) Stimulation by cathodal pulses of short duration. Current strength: $a$; $11, b ; 10 \times 10^{-10} \mathrm{~A}$. Several traces were superposed by repeating the sweeps once per second. Voltage calibration; $50 \mathrm{mV}$. Time marker; $1 \mathrm{msec}$. for $b, a$ was recorded by more expanded sweep and shows that the rising phase of the action potential had also the second inflection point (marked by a dot).

stimulation had a step on its rising phase similar to the second inflection point $\left(N_{2}\right.$ in fig. 7$)$ of the indirectly evoked action potential (fig. $13(B),(C)$ ). Such a step was first reported in toads' motoneurones (Araki and Otani, 1955) and later was confirmed also in cats' motoneurones (Frank and Fuortes, 1956; Fatt, 1957; Eccles, 1957). In spinal ganglion cells this was observed in almost all cases (in 95\% of 45 examples), and because this inflection point should be considered to be formed by the super-

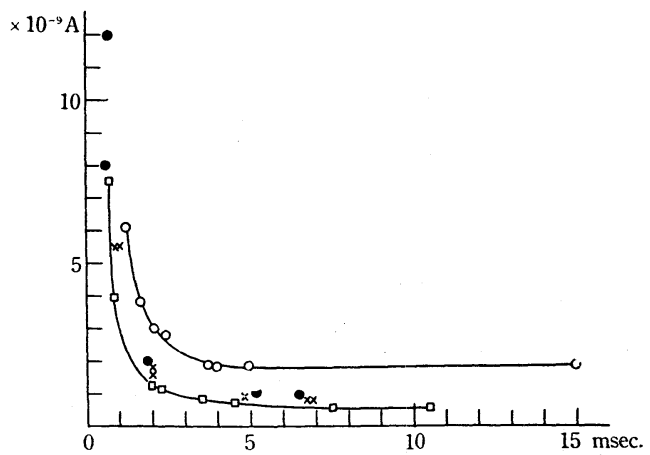

FIG. 14. Strength-duration curve obtained from 4 cells. Ordinate; current strength: Abscissa; current duration. position of S spike upon NM spike, it must be concluded that the non-myelinated segment was first excited, by which the cell body was activated later (see Eccles, 1957).

When the action potential was evoked by the direct stimulation, its magnitude, being measured from the resting level, was usually reduced than that of 
the one evoked indirectly (fig. $13(B)$ ). This difference was between 1.8 and $10.2 \mathrm{mV}$ (mean of 12 units, $4.8 \mathrm{mV}$ ) when the rheobasic current was used as a direct stimulus. This might be interpreted as that the membrane activity was affected by the cathodal current during the latency, because the magnitude of the indirectly evoked action potential was also reduced by the depolarisation (section $(F)$ ), and because such a difference became smaller with shortening of the latency. However, the question, whether the action potential, if it was evoked by a strong current with short latency, would have the same value as that of the indirectly evoked one, could not be answered, because a strong current introduced a large error into the measurement, being due to the nonlinear character of the electrode resistance.

By the strong cathodal current the cell membrane was sometimes activated repetitively under the temperature of more than $16^{\circ} \mathrm{C}$. Even in winter, when the preparation was warmed, double or tripple response was often observed by a current of 3-5 times the strength of the rheobasic current, but such a repeated firing of the long duration as is shown in fig. $13(A, d)$ was obtained only in spring (March or April). At the temperature of less than $16^{\circ} \mathrm{C}$. currents stronger than 10 times the rheobase usually failed to activate the cell membrane more than once.

\section{E. Impedance of the cell membrane}

Assuming the cell membrane to be a simple network having a resistance in parallel with a capacitance, the membrane impedance was determined by the aid of rectangular currents, as was done in spinal motoneurones (Araki and Otani, 1955; Frank and Fuortes, 1956; Eccles, 1957). When the current of long duration was employed, the depolarised potential always reached a steady level after the initial rising phase of a few milliseconds, where a local response or an action potential was superposed with increase of the current (fig. 15), and an example of the relationship between the applied current and the potential changes measured both in the initial phase and in the steady level is plotted in fig. 16. On the other hand the hyperpolarised potential, if it did not exceed $10-20 \mathrm{mV}$, also reached a nearly steady level, which was always of larger value than that obtained by the cathodal one of the same intensity, but if a stronger polarisation was given, a marked decrease of its amplitude was observed after it reached a maximum value during the initial $50-200 \mathrm{msec}$. Both the initial maximum value and the final reduced one obtained $10 \mathrm{sec}$. after the onset of the current are also plotted in fig. 16.

Using the current of $3 \times 10^{-10} \mathrm{~A}$, which was smaller than a half of the rheobase in almost all cases and usually did not cause the delayed decrease in the hyperpolarised potential, the value of the membrane resistance of the whole cell body was calculated, which ranged from 7 to $20 \mathrm{M} \Omega$ (mean of 6 cells, 16 $\mathrm{M} \Omega$ ) for the cathodal current and from 20 to $25 \mathrm{M} \Omega$ (mean, $22 \mathrm{M} \Omega$ ) for the anodal one (table 2). The slope resistance $d V / d I$ was reduced to 4-7 $\mathrm{M} \Omega$ under the depolarisation of more than $5 \mathrm{mV}$, but on the other hand it became as large as 30-70 M 2 under the hyperpolarisation of $20-40 \mathrm{mV}$.

The delayed decrease of the hyperpolarised potential could be interpreted as to be due to the reduction of the membrane resistance, which was proved 

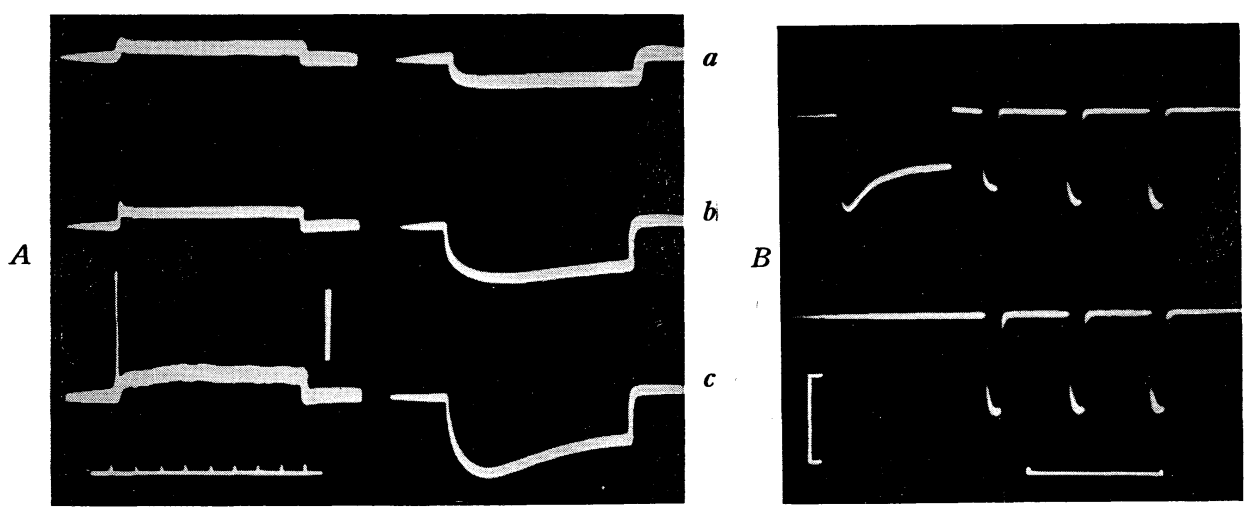

FIG. 15. Polarisation of the cell membrane by currents of long duration.

(A) Left; cathodal, right; anodal polarisation. Current strength: $a ; 5, b ; 10$, $c ; 15 \times 10^{-10}$ A. Voltage calibration; $50 \mathrm{mV}$. Time marker; $100 \mathrm{msec}$. Cell diameter; $60 \mu, 10^{\circ} \mathrm{C}$.

(B) After-effect of intense hyperpolarisation, tested by anodal pulses. Lower trace shows the effect of test pulses when the conditioning anodal current was not applied. Voltage scal; $60 \mathrm{mV}$. Time scale; $1 \mathrm{sec}$. Cell diameter; $\varepsilon 0 \mu, 18^{\circ} \mathrm{C}$.

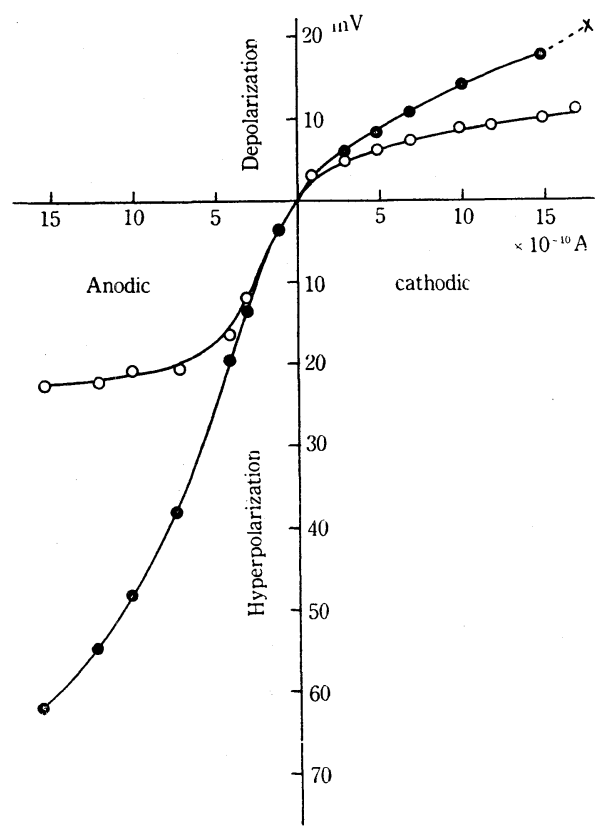

FIG. 16. Relatioinship between the polarising current (abscissa) and the polarised potential (ordinate). Closed circles show the initial maximum value and the opened ones the final value obtained $10 \mathrm{sec}$. after the onset of the current. The cross indicates the critical depolarisation for the rheobasic current. Cell diameter; $80 \mu, 15^{\circ} \mathrm{C}$.

by applying test pulses both during this delayed phase and after the cessation of the hyperpolarising current. As is shown in fig. $15(B)$, the reduced resistance of the cell membrane usually recovered to the orginal value during several seconds after the break of the current. The membrane resting potential usually decreased slightly (several millivolts) during this recovery period, but in some cases it was hardly noticed. The action potential evoked indirectly did not suffer from any change during this period.

The time-course of the polarised potential at the onset and cessation of rectangular currents was usually deviated from a simple exponential curve as 
is shown in fig. 17 , even when the current strength was as small as $3 \times 10^{-10} \mathrm{~A}$. The depolarised potential rose or fell more rapidly than did an exponential curve which was followed by its initial part, while the rising phase of the hyperpolarised potential was so protracted that it took usually more than 50 msec. to reach the maximum value. Its falling phase was faster in some cases but slower in others than was expected by an exponenential curve (table 1). Furthermore, the falling phase of both depolarised and hyperpolarised potential often showed a rebound to the opposite direction crossing the resting level,

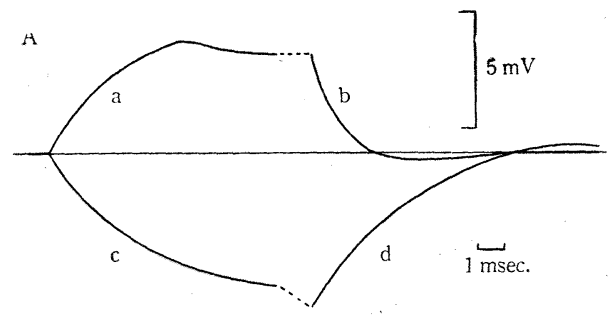

Fig. 17. Time-course of the polarised potential at the onset and cessation of rectangular currents.

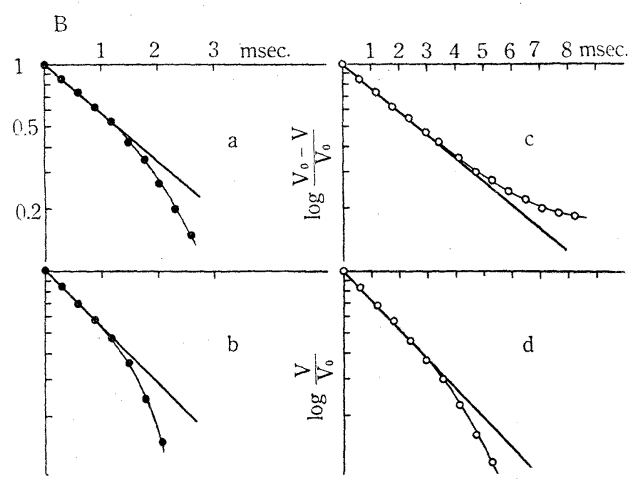

(A) Traces of the rising and falling phase of both cathodal and anodal polarisation produced by a rectangular current of intensity $3 \times 19^{-10} \mathrm{~A}$ and of duration $30 \mathrm{msec}$. Cell diameter; $80 \mu, 18^{\circ} \mathrm{C}$.

(B) The time-course of the polarised potential, which is traced in $(A)$, is plotted in logarithmic scale. $a$; rising phase of depolarisation: $b$; falling phase of depolarisation: $c$; rising phase of hyperpolarisation: $d$ : falling phase of hyperpolarisation. $V$; polarised potential. $V_{0}$; polarised potential at the steady level, where the rising phase reached or the falling phase started. Straight line shows the initial time-course, by which the ideal time-constant was calculated (see text).

TABLE 1. Time-Course of the Polarised Potential at the Onset and Cessation of Rectangular Currents of Intensity $3 \times 10^{-10} \mathrm{~A}$

\begin{tabular}{|c|c|c|c|c|c|c|c|c|}
\hline \multirow{3}{*}{$\begin{array}{c}\text { Obtained from } \\
\text { No. } \downarrow\end{array}$} & \multicolumn{4}{|c|}{ Depolarisation } & \multicolumn{4}{|c|}{ Hyperpolarisation } \\
\hline & \multicolumn{2}{|c|}{ Rising phase } & \multicolumn{2}{|c|}{ Falling phase } & \multicolumn{2}{|c|}{ Rising phase } & \multicolumn{2}{|c|}{ Falling phase } \\
\hline & $\begin{array}{c}a \\
(\mathrm{msec} .)\end{array}$ & $\begin{array}{c}b \\
\text { (msec.) }\end{array}$ & $\begin{array}{c}a \\
\text { (msec.) }\end{array}$ & $\begin{array}{c}b \\
\text { (msec.) }\end{array}$ & $\begin{array}{c}a \\
\text { (msec.) }\end{array}$ & $\begin{array}{c}b \\
\text { (msec.) }\end{array}$ & $\begin{array}{c}a \\
\text { (msec. }\end{array}$ & $\begin{array}{c}b \\
\text { (msec.) }\end{array}$ \\
\hline 1 & 2.1 & 1.8 & 1.5 & 1.8 & 4.5 & 4.5 & 3.3 & 3.2 \\
\hline 2 & 3.0 & 3.0 & 2.7 & 2.7 & 4.0 & 4.0 & 6.8 & 6.7 \\
\hline 3 & 1.6 & 1.6 & 2.1 & 1.9 & 4.6 & 12.0 & 5.2 & 7.5 \\
\hline 4 & 2.3 & 2.3 & 2.0 & 2.0 & 4.0 & 4.5 & 3.5 & 3.5 \\
\hline 5 & 1.5 & 1.5 & 1.8 & 1.2 & 4.2 & 4.5 & 3.0 & 3.0 \\
\hline 6 & 2.3 & 2.3 & 2.8 & 2.7 & 5.5 & 10.6 & 7.0 & 10.0 \\
\hline Mean & 2.13 & 2.08 & 2.15 & 2.05 & 4.47 & 6.68 & 4.80 & 5.65 \\
\hline
\end{tabular}

$a$; time-course of the ideal exponential curve, which was determined by the initial phase of the transient change of the polarised potential. $b$; time to reach the value of $1 / e$ or $(e-1) / e$ of the polarised potential. Measurements were done on 6 cells. 
TABLE 2. Impedance of the Cell Membrane

\begin{tabular}{|c|c|c|c|c|c|c|c|c|c|c|c|c|c|}
\hline \multirow[b]{2}{*}{ No. } & \multirow{2}{*}{$\begin{array}{c}\text { Dia- } \\
\text { meter } \\
(\mu)\end{array}$} & \multicolumn{2}{|c|}{$r(\mathrm{M} \Omega)$} & \multicolumn{2}{|c|}{$R\left(\mathrm{k} \Omega \mathrm{cm}^{2}.\right)$} & \multicolumn{2}{|c|}{ T.C. (msec.) } & \multicolumn{3}{|c|}{$c(\mu \mu \mathrm{F})$} & \multicolumn{3}{|c|}{$C\left(\mu \mathrm{F} / \mathrm{cm}^{2}.\right)$} \\
\hline & & $d$ & $h$ & $d$ & $h$ & $d$ & $h$ & $d$ & $h$ & Mean & $d$ & $h$ & Mean \\
\hline 1 & 70 & 14.2 & 22.3 & 2.18 & 3.44 & 1.80 & 3.90 & 127 & 174 & 151 & 0.84 & 1.12 & 0.98 \\
\hline 2 & 80 & 20.7 & 25.4 & 4.15 & 5.10 & 2.85 & 5.40 & 136 & 215 & 17 & 0.68 & 1.06 & 0.87 \\
\hline 3 & 80 & 11.7 & 22.3 & 2.35 & 4.50 & 1.85 & 4.90 & 158 & 220 & 18 & 0.78 & 1.09 & 0.94 \\
\hline 4 & 70 & 15.7 & 20.7 & 2.42 & 3.17 & 2.15 & 3.75 & 136 & 180 & $15 \varepsilon$ & 0.88 & 1.19 & 1.04 \\
\hline 5 & 60 & 12.3 & 21.3 & 1.37 & 2.42 & 1.65 & 3.60 & 134 & 169 & 152 & 1.20 & 1.49 & 1.35 \\
\hline 6 & 90 & 7.2 & 21.8 & 1.82 & 5.53 & 2.55 & 6.25 & 355 & 284 & 320 & 1.40 & 1.11 & 1.26 \\
\hline Mean & & 16.3 & 22.3 & 2.25 & .03 & 2.14 & 4.63 & 174 & 207 & 191 & 0.96 & 1.18 & 1.07 \\
\hline
\end{tabular}

$r$; membrane resistance. $R$; specific membrane resistance. T.C.; mean time-constant of the rising and falling phase. $c$; membrane capacitance per cell calculated by $r$ and T.C. $C$; specific membrane capacitance. Cell diameter was measured by an eyepiece micrometer. Measurements were done on the same examples as those of table $1 . d$; values obtained by cathodal currents. $h$; the one obtained by anodal currents.

which was $0.5 \mathrm{mV}$ or so in magnitude, though it became slightly larger with both prolongation of the current duration and increase of the current intensity. This rebould could not be attributed to the non-linear character of electrode resistance, which was tested with the electrode dipped in Ringer solution or in an isotonic $\mathrm{KCl}$ solution.

These deviations of the polarised potential from the exponential curve would be due to complicated properties of the cell membrane and might be avoided to some extent if the current of much smaller intensity than that used here is employed, which, however, would introduce much larger errors into the measurements. Therefore, the membrane time-constant and membrane capacitance were obtained from the polarised potential produced by a rectangular current of $3 \times 10^{-10}$ according to the following approximation. As is shown in fig. 17 the initial part of the transient change of the membrane potential at the onset and cessation of currents usually followed an exponential curve. This was assumed to be an ideal curve, along which the membrane potential would have increased or decreased if other factors than a simple CR network did not take part in its time-course. The measured values of the time-constant of this ideal curve are shown in table 1 with those of the time, where the actual polarised potential rose to $(e-1) / e$ of the final value or fell to $1 / e$ of the original value. The difference of the time-constant between the ideal and real potential changes in the depolarisation was not very much, but it was considerably larger in the hyperpolarisation. It might be reasonable to give here the mean values of the time-constants of the rising phase and that of the falling phase obtained from the ideal curve as the probable time-constant of the cell membrane, $i e ., 2.1 \mathrm{msec}$. for the depolarisation and $4.6 \mathrm{msec}$. for the hyperpolarisation (mean value of 6 cells).

Frank and Fuortes (1956) calculated the membrane time-constant from the strength-latency curve on spinal motoneurones of cats. The value obtained from the strength-duration curve (fig. 14) by the same principle as theirs was 1.53.1 msec. (mean of 4 cell, 2.2 msec.). When a cathodal pulse of short duration 
was employed for obtaining the strength-duration curve, local responses or action potentials appeared after break of the current, which, therefore, did not introduced large errors into this calculation, but complications similar to the method described above would be also inevitable.

The membrane capacitance was then calculated from the values of the membrane resistance and the mean time-constant of the rising and falling phase (table 2). When the ideal time-constant was used for the calculation, the value of the slope resistance at the membrane potential, where the transient change of the polarised potential started, should be employed as the effective resistance, because the membrane resistance changed considerably with the alteration of the membrane potential as is shown in fig. 16. However, it was substituted in the present experiments by the value, obtained dividing the polarised potential by the current strength, in order to avoid a further complication to be introduced into measurements, but it might be compensated to some extent by using the mean value of the time-constants meaured by the rising and falling phase in the calculation. Furthermore, it might be reasonable to give here the mean value of the capacitance obtained by cathodal currents and that by anodal currents as the probable value of the membrane capacitance. The calculated values, which ranged from 150 to $320 \mu \mu \mathrm{F}$, are shown in table 2 with the values of the membrane resistance and the mean time-constant.

Assuming the cell body to be a perfect sphere, its surface area can be calculated with its diameter measured directly; for example, when the diameter is $60,70,80$ or $90 \mu$, the corresponding value of the surface area is $113,154,201$ or $254 \times 10^{-6} \mathrm{~cm}^{2}$. respectively. From this the specific resistance and capacitance of the cell membrane were calculated. As is shown in table 2, the former was $2.2 \mathrm{k} \Omega \mathrm{cm}^{2}$. for the cathodal current and $4.0 \mathrm{k} \Omega \mathrm{cm}^{2}$. for the anodal one, and the latter was $1.0 \mu \mathrm{F} / \mathrm{cm}^{2}$. as the mean value of 6 cells.

The value of the specific membrane resistance is considerably higher than that of the spinal motoneurones, i.e., $365 \Omega \mathrm{cm}^{2}$. in toads (Araki and Otani, 1955), $500 \Omega \mathrm{cm}^{2}$. (Coombs et al., $1955 \mathrm{a}$ ) and 1,000 $\Omega \mathrm{cm}^{2}$. (Frank and Fuortes, 1956) in cats, but it is of the same order as that of muscle fibers $\left(4 \mathrm{k} \Omega \mathrm{cm}^{2}\right.$., Fatt and Katz, 1951). The membrane time-constant of $2.1 \mathrm{msec}$. for the cathodal current in the spinal ganglion cell is not much different from that of the spinal motonenrones of cats, i.e., $1.4 \mathrm{msec}$. (Frank and Fuortes, 1956) or $2.5 \mathrm{msec}$. (Eccles, 1957); and its specific capacitance of $1.0 \mu \mathrm{F} / \mathrm{cm}^{2}$. is of the same order as that of the squid giant axon $\left(1.1 \mu \mathrm{F} / \mathrm{cm}^{2}\right.$., Curtis and Cole, 1938) as well as that of Frank and Fuortes' results on spinal motoneurones $\left(1.0-1.5 \mu \mathrm{F} / \mathrm{cm}^{2}\right.$., 1956).

\section{F. The effect of the polarisation upon the action potentials}

When the membrane potential was altered by the polarising current, the indirectly evoked action potential showed corresponding changes. Under the depolarised state it became smaller in magnitude and slower in its time-course, which resembled that observed under the injury. On the contrary, under the hyperpolarisation it became larger in magnitude and its maximum rate of rise and fall increased (fig. 18). Both the reduction and the augmentation of the spike height were always larger than the change of the membrane potential, 
which showed that the polarising current not only changed the membrane potential but also affected the membrane activity (cf. Araki and Otani, 1955; Eccles, 195̄7).

When the cell membrane was injured, these effects apperared more remarkably, i.e., the increase in the membrane potential at the spike peak was often amounted to $50 \mathrm{mV}$ under the hyperpolarisation of $20-30 \mathrm{mV}$, and on the other hand a small depolarisation could make the membrane of the cell body inactive and caused easily the conduction block from NM spike to S spike (cf. Coombs et al., $1955 \mathrm{a}$ ). Even when the indirect stimulation could evoke nothing but M spike or small NM spike, the hyperpolarising current usually recovered the membrane activity to the extent that S spike could appear, which, however, deteriorated in a long run unless the electrode tip could be resealed.

When the cell membrane was hyperpolarised, the two inflection points on the rising phase of the action potential became more prominent, and furthermore, the conduction could be blocked usually between the node of axon and the non-myelinated segment (fig. $18(c)$ ), but in some cases the conduction block between the latter and the cell body was observed. Because the delayed decrease occurred in the hyperpolarised potential as is described in section $(E)$, such an effect of the hyperpolarisation as necessary for the conduction block was only obtained at its early stage (fig. $18(d)$ ).

\section{G. Another type of ganglion cells}

When a small cell with a diameter of 60-6j $\mu$ was impaled, it showed sometimes, but not always, different properties from those described above. First, the indirect stimuli, even when
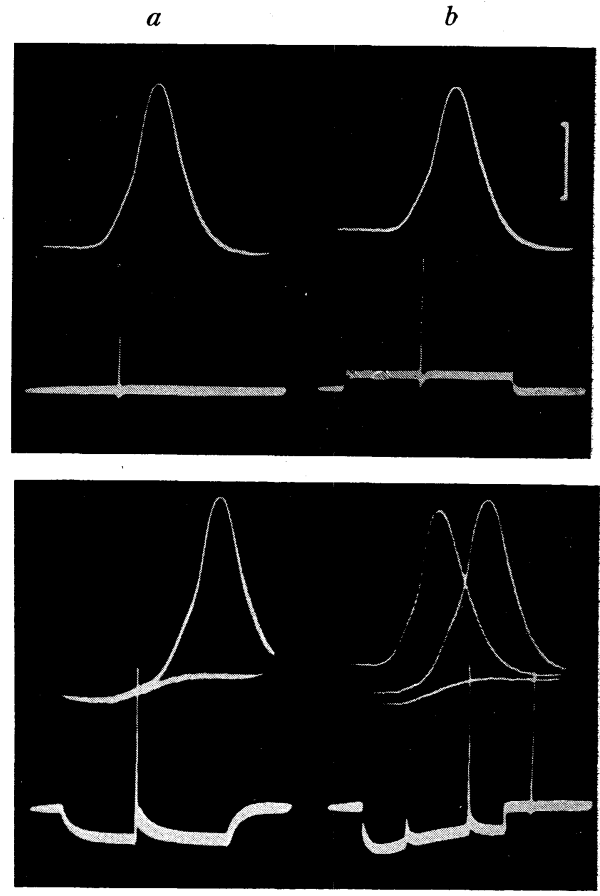

$c$ $d$

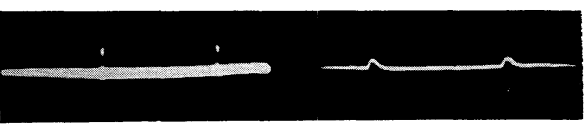

$100 \mathrm{msec}$.

$1 \mathrm{msec}$.

FIG. 18. Effect of polarisation on the action potential evoked by indirect stimuli. Upper and lower traces in each frame were obtained simultaneously by two oscilloscopes as is shown in fig. 7 . $a$; action potential without polarisation, $b$; cathodal polarisation, $C$; anodal polarisation. Two sweeps were superimposed in order to show the critical condition for block. $d$; effect of the delayed decrease of the membrane resistance under the strong anodal current. Three indirect stimuli were applied both during and after the hyperpolarisation. Voltage scale; $50 \mathrm{mV}$. Time markers; $1 \mathrm{msec}$. for the upper traces and $100 \mathrm{msec}$. for the lower ones except in $(d)$, where sweep velocity was made slower than others. 
it was intensified up to $40 \mathrm{~V}$, usually failed to evoke any response from it. It could not be settled whether this was due to the failure of the stimulation or to a conduction block, but in an example action potentials could be evoked indirectly with an extremely long latency, and the conduction velocity measured by it was about $0.3 \mathrm{~m} / \mathrm{sec}$. along either the dorsal root or the peripheral nerve. Second, the action potential evoked directly showed nearly the same magnitude of about $100 \mathrm{mV}$ as the ordinary ones, but its duration was always much longer (6-13 msec.) than the latter. The rising phase had an inflection point just like $N_{2}$ in fig. 7, while its falling phase always showed a hump as marked as that of the spinal ganglion cells of cultured chick embryo (Crain, 1956), though it sometimes appeared in the ordinary type of cells described above. Third, the membrane properties were also different from the ordinary ones, though detailed observations were limited by the difficulty of the impalement and measured values described below were obtained from only three cells. The membrane time-constant obtained by the same method as described in section $(E)$ was remarkably larger $(6.5-8.5 \mathrm{msec}$. for the cathodal current) than that obtained from large cells. The specific resistance of the membrane was $3.8-3.9 \mathrm{k} \Omega \mathrm{cm}^{2}$. for the cathodal current and $5.0-6.5 \mathrm{k} \Omega \mathrm{cm}^{2}$. for the anodal one; and the specific membrane capacitance was $1.7-2.2 \mu \mathrm{F} / \mathrm{cm}^{2}$. The critical depolarisation for direct stimuli was higher $(26.5-28.0 \mathrm{mV})$ than for the large cell. Moreover, it was of interest to note that the delayed decrease of the membrane resistance for strong hyperpolarising current was not observed in these small cells, although the rectification was as remarkable as in large cells.

Such a kind of cells as is described here was supposed to be those which were connected to unmyelinated axons because of their smaller size, but a further detailed study should be necessary to clarify the property of these small cells.

\section{DISCUSSION}

The resting potential of the spinal ganglion cell of toads obtained in the present experiments was between 50 and $80 \mathrm{mV}$, which agrees with that in other nerve cells, i.e., about $70 \mathrm{mV}$ in cats' spinal motoneurones (Brock et al., 1952), $40-50 \mathrm{mV}$ in those of toads (Araki and Otani, 1953), 70-80 mV in stretch receptor cells of crayfish (Eyzaguirre and Kuffler, $1955 \mathrm{a}$ ), $65-75 \mathrm{mV}$ in sympathetic ganglion cells of rabits (R. M. Eccles, 1955) and $50-65 \mathrm{mV}$ in spinal ganglion cells of cultured chick embryo (Crain, 1956). However, as is shown in fig. 8 , the measured values of the resting potential scattered considerably and was often as small as $50-60 \mathrm{mV}$. This could be accounted for by the following three reasons: First, the measurements were done throughout a year under various conditions; second, peneteration of the cell membrane with a electrode tip could cause a reduction and a fluctuation in resting potential; and third, the junctional potential of microelectrodes would have introduced errors into the measurements, because the electrodes having sharp tip and applicable to successful impalements had usually the junctional potential of $20-60 \mathrm{mV}$ in contact with Ringer solution. Such electrodes could introduce an error of 10- 
$20 \mathrm{mV}$ into the value of the measured resting potential (Adrian, 1956).

The after-positivity following the action potential of a squid giant axon (the positive phase) has been expalined by the ionic hypothesis (Hodgkin, 1951), as to be due to the delayed rise in the potassium conductance of the cell membrane during the falling phase of the action potential. The same explanation was adopted by Araki and Otani (1955) for that observed in toads' spinal motoneurones. The relationship between the magnitude of the after-positivity and the membrane potential, described in Results, suggests that the maximum value of the after-positivity depends on the equilibrium potential of a particular ion such as potassium. The slope of the curve relating its magnitude to the membrane potential was nearly unity, which is not much different from the value of 0.82 obtained in stretch receptor cells of crayfish (Eyzaguirre and Kuffler, $1955 \mathrm{~b}$ ), but the diviation from this line under the depolarisation was not found in the latter. This deviation might suggest that permeability change to other ions takes part during the period of the after-positivity under the depolarisation. The time-course of the repolarisation phase of the after-positivity is slower than that expected from the resting membrane time-constant, which should be due to slow recovery of the permeability change underlying the afterpositivity.

The membrane resistance was reduced under the depolarisation, while it increased under the hyperpolarisation. From this view point the membrane of toads' spinal ganglion cells is of similar nature to that of the squid giant axon (Cole and Curtis, 1941; Hodgkin, Huxley and Katz, 1953), but it is different from that of the spinal motoneurones (Coombs et al., 1955 a). However, the delayed decrease of the membrane resistance for intense hyperpolarising currents has not been found in other tissues. In slow muscle fibers of frogs (Burke and Ginsborg, 1956) the depolarised potential was found to show a delayed reduction, which was supposed to be due to a permeability increase to potassium ions, because a transient hyperpolarisation followed after the termination of the cathodal current, the magnitude of which seemed to be related to the equilibrium potential of potassium ions and was affected actually by the external potassium concentration. On the other hand the delayed reduction of the hyperpolarised potential in the spinal ganglion cells accompanied only a small depolarisation after the break of the current, which could not be detected sometimes. Therefore, the delayed reduction of the hyperpolarised potential could not be attributed to the permeability change to potassium ions only, the equilibrium potential of which should be larger than the resting potential by several millivolts, if the after-positivity was considered to indicate it. The equilibrium potential of chloride ions was evaluated as to be smaller than that of potassium ions and to be close to the resting potential in Loligo axons and frog muscles (Hodgkin, 1951) and in spinal motoneurones (Coombs et al., 1955 b), and consequently it may be possible that the delayed reduction of the membrane resistance could be due to an incerase of the permeability to chloride ions.

The time-course of the polarised potential caused by rectangular currents was different from that of a simple exponential curve, which would be due to 
following four reasons: First, a local response could superpose on the rising phase of the depolarised potential; second, the falling phase of both depolarised and hyperpolarised potentials was affected by a process, which caused a rebound to the opposite direction overshooting the resting level; third, the slope resistance of the membrane varied much with alteration of the membrane potential; fourth, the rising phase of the hyperpolarised potential was much protracted than the falling one, which could be related to the delayed reduction of the membrane resistance.

\section{SUMMARY}

1) The electrical properties of the spinal ganglion cell of toads were investigated with intracellular microelectrodes.

2) A preamplifier was deviced in order to use one and the same electrode both for recording and for stimulation. The principle and the actual circuit were described.

3) The successful impalement was achieved with microelectrodes of a finer tip and by readjusting the electrode position after penetration of the ganglion cells, judging the condition of the cell membrane by anodal pulses.

4) The resting potential obtained were between 50 and $80 \mathrm{mV}$, and the action potentials $80-125 \mathrm{mV}$.

5) The rising phase of the action potential had two inflection points, suggesting the three-step conduction from the axon to the cell body. Corresponding to them three component potentials of different configuration could be isolated from each other. They were named as S spike, NM spike and $\mathrm{M}$ spike.

6) The falling phase of the action potential was followed by an after-positivity, and the relation between its magnitude and the membrane potential was investigated.

7) The rheobasic current and the critical depolarisation for the direct stimulation with the impaled microelectrode were $1.2 \times 10^{-9} \mathrm{~A}$ and $17 \mathrm{mV}$ respectively. The rising phase of the directly evoked action potential had in almost all cases one inflection point, suggesting that the non-myelinated segment was first excited and the cell body was activated later.

8) The electrical resistance and capacitance of the cell membrane were measured by applying pulses directly to the cell membrane. The respective values obtained were $2.2 \mathrm{k} \Omega \mathrm{cm}^{2}$. for the cathodal current and $4.0 \mathrm{k} \Omega \mathrm{cm}^{2}$. for the anodal one, and $1.0 \mu \mathrm{F} / \mathrm{cm}^{2}$.

9) For strong hyperpolarising currents the membrane resistance was reduced after it attained to the maximum value, and it took several seconds to recover to the original value after the break of currents.

10) The polarising current affected the membrane activity, and the conduction from $M$ spike to NM spike or from the latter to $S$ spike was blocked by a suitable hyperpolarising current.

The author wishes to acknowledge the encouragement and criticism of Dr. Masayasu Sato and the help of Mr. Masanobu Saiga for this investigation and manuscription. A part of the expense of this work was supported by a grant from the Ministry of Eduçation. 


\section{REFERENCES}

1. ADRIAN, R. H. The effect of internal and external potassium concentration on the membrane potential of frog muscle. J. Physiol. 133: 631-658, 1956.

2. Araki, T., Otani, T. AND Furukawa, T. The electrical activities of single motoneurones in toad's spinal cord, recorded with intracellular electrodes. Jap. J. Physiol. 3: 254-267, 1953.

3. ARAKI, T. AND OTANI, T. Response of single motoneurons to direct stimulation in toad's spinal cord. J. Neurophysiol. 18: 472-485, 1955.

4. BRock, L. G., CoOMBS, J. S. AND Eccles, J. C. The recording of potentials from motoneurones with an intracellular eleotrode. J. Physiol. 117: 431-460, 1952.

5. BRock, L. G., CoOmBs, J. S. AND ECcLES, J. C. Intracellular recording from antidromically activated motoneurones. J. Physiol. 122: 429-461, 1953.

6. Burke, W. AND Ginsborg, B. L. The electrical properties of the slow muscle fiber membrane. J. Physiol. 132: 586-598, 1956.

7. Cole, K. S. AND Curtis, H. J. Membrane potential of the squid giant axon during current flow. J. gen. Physiol. 24: 551-563, 1941.

8. Coombs, J. S., Eccles, J. C. AND FAtT, P. The electrieal properties of the motoneurone membrane. J. Physiol. 130: 291-325, 1955 a.

9. CoOmbs, J. S., Eccles, J. C. AND FATT, P. The specific ionic conductances and the ionic movements across the motoneuronal membrane that produced the inhibitory post-synaptic potential. J. Physiol. 130: 326-373, $1955 \mathrm{~b}$.

10. CRAIN, S. M. Resting and action potentials of cultured chick embryo spinal ganglion cells. J. comp. Neurol. 104: 285-330, 1956.

11. Curtis, H. J. AND COLE, K. S. Transverse electric impedance of the squid giant axon. J. gen. Physiol. 21: 757-765, 1938.

12. DRAPER, M. H. AND WEIDMANN, S. Cardiac resting and action potentials recorded with an intracellular electrode. J. Physiol. 115: 74-94, 1951.

13. ECClES, J. C. The neurophysiological basis of mind. Oxford: Claredon Press, 1953.

14. ECCLES, J. C. The physiology of nerve cells. Baltimore: The Johns Hopkins Press, 1957.

15. ECCLES, R. M. Intracellular potentials recorded from a mammalian sympathetic ganglion. J. Physiol. 130: 572-584, 1955.

16. Eyzaguirre, C. AND Kuffler, S. W. Processes of excitation in the dendrites and in the soma of single isolated sensory nerve cells of the lobster and crayfish. J. gen. Physiol. 39: 87-119, 1955 a.

17. Eyzaguirre, C. AND Kuffler, S. W. Further srudy of soma, dendrite, and axon excitation in single neurons. J. gen. Physiol. 39: 121-153, $1955 \mathrm{~b}$.

18. FATT, P. AND KATZ, B. An analysis of the end-plate potential recorded with an intracellular electrode. J. Physiol. 115: 320-370, 1951.

19. FAtT, P. Sequence of events in synaptic activation of a motoneurone. J. Neurophysiol. 20: 61-80, 1957.

20. FRANK, K. AND FUORTES, M. F. G. Stimulation of single motoneurones with intracellular electrodes. J. Physiol. 134: 451-470, 1956.

21. HAAPANEN, L. AND OTtoson, D. A frequency compensated input unit for recording with microelectrodes. Acta. Physiol. Scandinav. 32: 271-280, 1954.

22. Hodgkin, A. L. The subthreshold potentials in a crustacean nerve fibre. Proc. Roy. Soc. B. 126: 87-121, 1938.

23. Hodgkin, A. L. The ionic basis of electrical activity in nerve and muscle. Biol. Rev. 26: 339-409, 1951.

24. Hodgkin, A. L., Huxley, A. F. And KAtZ, B. Measurement of current-voltage relations in the membrane of the giant axon of Loligo. J. Physiol. 116: 424-448, 1952.

25. JENERICK, H. P. AND GERARD, R. W, Membrane potential and threshold of single 
muscle fibers. J. cell. comp. Physiol. 42: 79-102, 1953.

26. KATZ, B. Experimental evidence for non-conducted response of nerve to subthreshold stimulation. Proc. Roy. Soc. B. 124: 244-276, 1937.

27. LenhosséK, M. v. Untersuchungen über die Spinalganglien des Frosches. Arch. mikr. Anat. 26: 370-453, 1886.

28. MACNICHOL, E. F. A high-impedance input circuit suitable for electrophysioiogical recording from micropipette electrodes. Nav. Med. Research. Inst. 97-117, 1954.

29. Miller, S. E. Sensitive D.C amplifier with A-C operation. Electronics Nov: 27-31, 1941.

30. NAstuk, W. L. AND Hodgkin, A. L. The electrical activity of single muscle fibres. J. cell. comp. Physiol. 35: 39-73, 1950.

31. SchmitT, O. H. AND DUBBERT, D. R. Tissue stimulators utilizing radio-frequency coupling. Rev. Sci. Instr. 20: 170-173, 1949.

32. Solms, S. J., NAStuk, W. L. And Alexander, J. T. Development of a high-fidelity preampifier for use in the recording of bioelectric potentials with intracellular electrodes. Rev. Sci. Instr. 24: 960-967, 1953.

33. Svaetichin, G. Analysis of action potentials recorded from single spinal ganglion cells. Acta. Physiol. Scandinav. 24: 23-57, 1951.

34. Svaetichin, G. A technique for oscillographic recording of spectral response curves. Acta. Physiol. Scandinav. 39: 3-16, 1956.

35. TASAKi, I., Polley, E. H. AND OrRego, F. Action potentials from individual elements in cat geniculate and striate cortex. J. Neurophysiol. 17: 454-474, 1954.

36. TOMITA, T. AND TORIHAmA, Y. Further study on the intraretinal action potentials and on the site of ERG generation. Jap. J. Physiol. 6: 118-136, 1956. 